\title{
Introduction of Vaccinomics to Develop Personalized Vaccines in Light of Changes in the Usage of Hantaan Virus Vaccine (Hantavax ${ }^{\circledR}$ ) in Korea
}

\author{
Jong-Myon Bae \\ Department of Preventive Medicine, Jeju National University School of Medicine, Jeju, Korea
}

The Ministry of Food and Drug Safety of Korea made an official announcement in March 2018 that the total number of inoculations of Hantaan virus vaccine $\left(\right.$ Hantava $\left.^{\circledR}\right)$ would change from 3 to 4 . Some aspects of this decision remain controversial. Based on the characteristics of Hantaan virus (HTNV) and its role in the pathogenesis of hemorrhagic fever with renal syndrome, it might be difficult to develop an effective and safe HTNV vaccine through the isolate-inactivate-inject paradigm. With the development of high-throughput 'omics' technologies in the 21st century, vaccinomics has been introduced. While the goal of vaccinomics is to develop equations to describe and predict the immune response, it could also serve as a tool for developing new vaccine candidates and individualized approaches to vaccinology. Thus, the possibility of applying the innovative field of vaccinomics to develop a more effective and safer HTNV vaccine should be considered.

Key words: Hantaan virus, Hemorrhagic fever with renal syndrome, Synthetic vaccines, Immunogenetics, Precision medicine

\section{CONTROVERSIES ABOUT THE CHANGE IN THE USAGE OF HANTAVAX ${ }^{\circledR}$ IN 2018}

In March 2018, the Central Pharmaceutical Affairs Council of the Ministry of Food and Drug Safety (MFDS) decided to change the total number of inoculations of Hantaan virus vaccine (Hantavax ${ }^{\circledR}$, Korea Green Cross, Seoul, Korea), which had been developed to prevent hemorrhagic fever with renal syndrome (HFRS), from 3 to 4 [1]. And the MFDS removed all conditions for clinical effectiveness and long-term immunity mea-

Received: January 6, 2019 Accepted: August 2, 2019

Corresponding author: Jong-Myon Bae, MD, PhD Department of Preventive Medicine, Jeju National University School of Medicine, 102 Jejudaehak-ro, Jeju 63243, Korea

E-mail: jmbae@jejunu.ac.kr

This is an Open Access article distributed under the terms of the Creative Commons Attribution Non-Commercial License (http://creativecommons.org/licenses/bync/4.0/) which permits unrestricted non-commercial use, distribution, and reproduction in any medium, provided the original work is properly cited. surements when Hantavax ${ }^{\circledR}$ received conditional approval in July 1990, most likely because they concluded that the results for long-term immunogenicity were valid. The content of the discussions among members in the decision-making process has been released in the form of minutes, which author considered to shed light on the following 3 major issues.

First, it can be inferred that immunogenicity was judged based on an 1:10 seropositivity rate of neutralizing antibody. The following 4 major measurement methods were applied in studies investigating the Hantavax ${ }^{\circledR}$ immunogenicity: immunofluorescent assay, enzyme-linked immunosorbent assay, high-density particle agglutination, and the plaque reduction neutralizing antibody test. The problem is that the seropositivity rate is interpreted differently depending on the method, even for the same sample [2].

Second, the decision-making process did not account for the fact that maintaining immunogenicity over the long-term with boosting is distinct from ensuring vaccine effectiveness 
(VE) [3]. Moreover, as Hantavax ${ }^{\circledR}$ has been used to inoculate members of high-risk groups since it received marketing approval 30 years ago, the use of Hantavax ${ }^{\circledR}$ should be reexamined to determine the VE through post-market investigations and research, instead of the seropositivity rate. As of December 2018, 3 papers dealing with the VE of Hantavax ${ }^{\circledR}$ [4-6] were found in a search of KoreaMed (https://koreamed.org) and PubMed (https://www.ncbi.nlm.nih.gov/pubmed/). The study of Chu et al. [4], which was a randomized field trial conducted in Yugoslavia and published in 1999, showed no occurrence of disease in 1900 patients vaccinated with Hantavax ${ }^{\circledR}$, but occurrence in 20 of 2000 people in the placebo group. Based on this, it could be inferred that the existing protocol of 3 rounds of inoculation has an adequate VE. The study of Park et al. [5] published in 2004, in which a case-control study was conducted on 57 soldiers, found that the VE was not statistically significant. This result means the marketing approval for the current Hantavax ${ }^{\circledR}$ vaccine should be examined first, before any debates on the number of inoculations, although it should be kept in mind that further research is needed due to the small subject size, as the authors pointed out. The study of Jung et al. [6], which was published in 2018, conducted a casecontrol study of 100 soldiers between July 2011 and February 2011. One or more inoculations showed a significant VE (78.7\%; $95 \%$ confidence interval, 9.1 to 95.0 ), but 2 or more inoculations did show a statistically significant VE. Therefore, the results of these 3 studies on VE imply that securing long-term immunogenicity by increasing the number of inoculations is distinct from the preventive effectiveness of the vaccine.

Third, it is difficult to understand the statement in the minutes that "We should accept the validity of Hantavax ${ }^{\mathbb{B}}$ in order to carry forward the plan (investigating long-term immunogenicity up to 60 months)" in a situation where the clinical outcomes for 4 months after an additional inoculation in the 4-inoculation group were submitted. This discrepancy occurred because the conditions for approval depending on the validation of long-term immunogenicity were eliminated by a showof-hands vote (yes or no). Furthermore, the discussion did not reflect the more recent suggestions of researchers that welldesigned field trials of the Hantavax ${ }^{\circledR}$ vaccine are needed $[2,7]$, and that research on cell immunity, as well as the neutralizing humoral immune response, is imperative [8]. Furthermore, there was no cost-benefit consideration whatsoever regarding the addition of an extra inoculation in the debate phase.

\section{LIMITATIONS OF THE CONVENTIONAL VACCINE DEVELOPMENT METHOD IN THE DEVELOPMENT OF HANTAAN VIRUS VACCINE}

Hantavax ${ }^{\circledR}$ is a vaccine that was developed by attenuating Hantaan virus (HTNV), a pathogen causing HFRS [9]. Various approaches exist for the development of vaccines to prevent HFRS [8], but the virologic characteristics of the pathogens and the clinical characteristics of HFRS make the development of effective and safe vaccines difficult.

First, it is difficult to find an appropriate animal model for research into the pathogenesis of HTNV [9]. Because HTNV does not cause disease in the animals that are known to be reservoirs of infection, despite a continuous state of infection in those animals.

Second, the various clinical symptoms of HFRS are caused by an increase of capillary permeability, which occurs as part of the immune response of an infected person, rather than due to the direct cytopathology of HTNV [10]. Since the severity of disease has no statistically significant association with the presence or absence of vaccination [11], further research on the immunological effects of the HTNV vaccine is needed.

Therefore, it is likely that the classical vaccine development process, proceeding through the stages of isolation, inactivation, and injection, will highly fail as an approach for preventing HFRS caused by HTNV [12]. Innovative methods of vaccine development need to be introduced [13].

\section{PROPOSAL TO APPLY VACCINOMICS FOR VACCINE DEVELOPMENT}

Although the classical vaccine development method led to the eradication of smallpox, less progress has been made in the development of vaccines for human immunodeficiency virus (HIV), hepatitis $C$ virus, dengue fever, malaria, and other major infectious diseases across the world $[12,14,15]$. Moreover, a prompt response is needed for the development of vaccines for emerging infectious diseases $[14,15]$.

As various "omics" have been established in the 21st century, research into the development of new vaccines has also drawn upon various related concepts (e.g., vaccinomics, system vaccinology, structure vaccinology, vaccine informatics, immune response network theory, reverse vaccinology, etc.) $[14,16]$. Vaccinomics is defined as a comprehensive research program 
Table 1. Five practical uses of vaccinomics

\begin{tabular}{ll}
\hline Method & \multicolumn{1}{c}{ Practical uses } \\
\hline Vaccinomics & - A tool for evaluation of immune responses \\
& - A tool in developing new vaccine candidates \\
& - A tool in developing individualized vaccinology approaches \\
& - A tool in adversomics \\
- Development of systems level models to support vaccinomics
\end{tabular}

'Modified from Poland et al. Semin Immunol 2013;25:89-103 [16].

that seeks to understand the immune processes of the vaccines to be injected and predicts their effect using omics techniques for vaccine development $[16,17]$. The term "vaccinomics" can be used in the same meaning as "system vaccinology" [18], which refers to the same framework, but emphasizes the application of methods from systems biology $[14,16]$. Additionally, adversomics, which aims to reduce the incidence of adverse events and to promote the safety of vaccines, is being applied [16].

Poland et al. [16] stated that the ultimate purpose of vaccinomics is to identify and predict the immune response, suggesting 5 domains for its application, as shown in Table 1. The process of vaccinomics for vaccine development is well explained by the flow charts presented in the papers of Oberg et al. [12], De Gregorio and Rappuoli [19], Mooney et al. [20], and Nakaya and Pulendran [21]. Through these processed, a yellow fever vaccine (YF-17D) has successfully been developed $[22,23]$, and active efforts are being made to develop vaccines against HIV [24], influenza [25], and various cancers [26,27]. As such, the application of vaccinomics can overcome the disadvantages of clinical tests, which require extensive resources in terms of time and cost $[16,28]$, and may also lead to the development of personalized vaccines $[16,29]$.

\section{Ethics Statement}

This paper is a special article so it did not need ethical consideration.

\section{CONCLUSION}

As a study has reported that HFRS is affected by genetic susceptibility because its clinical symptoms vary depending on differences in the human leukocyte antigen system, a personalized HTNV vaccine should be developed to maximize its safety and effectiveness. In other words, author suggests that developing a more effective and safer HTNV vaccine using vaccinomics should be considered as an urgent need, although studies should also investigate long-term immunogenicity (over the course of 5 years) in response to 4 inoculations of Hantavax ${ }^{\circledR}$.

\section{SUPPLEMENTAL MATERIALS}

Korean version is available at https://doi.org/10.3961/ jpmph.19.018.

\section{CONFLICT OF INTEREST}

The author has no conflicts of interest associated with the material presented in this paper.

\section{ACKNOWLEDGEMENTS}

This work was supported by the 2019 education, research and student guidance grant funded by Jeju National University.

\section{AUTHOR CONTRIBUTIONS}

All work was done by JMB.

\section{ORCID}

Jong-Myon Bae https://orcid.org/0000-0003-3080-7852

\section{REFERENCES}

1. Ministry of Food and Drug Safety. Online library of drugs and foods [cited 2018 Dec 16]. Available from: http://drug.mfds.go. $\mathrm{kr} / \mathrm{html} /$ boardLinkBody.jsp?p_menuld=040803\&p_boardSeq = 107\&p_seq $=3201 \& p \_s u b \_m e n u l d=04080301$ (Korean).

2. Oh MD, Lee JK. Milestones in history of adult vaccination in Korea. Clin Exp Vaccine Res 2012;1(1):9-17.

3. Halloran ME, Longini IM Jr, Struchiner CJ. Design and interpretation of vaccine field studies. Epidemiol Rev 1999;21(1):73-88.

4. Chu YK, Gligic A, Tomanovic S, Bozovjc B, Obradovic M, Woo $Y D$, et al. A field efficacy trial of inactivated hantaan virus vaccine (Hantavax (TM)) against hemorrhagic fever with renal syndrome (HFRS) in the endemic areas of Yugoslavia from 1996 to 1998. J Korean Soc Virol 1999;29(2):55-64 (Korean).

5. Park K, Kim CS, Moon KT. Protective effectiveness of hantavirus vaccine. Emerg Infect Dis 2004;10(12):2218-2220. 
6. Jung J, Ko SJ, Oh HS, Moon SM, Song JW, Huh K. Protective effectiveness of inactivated hantavirus vaccine against hemorrhagic fever with renal syndrome. J Infect Dis 2018;217(9): 1417-1420.

7. Sohn YM, Rho HO, Park MS, Kim JS, Summers PL. Primary humoral immune responses to formalin inactivated hemorrhagic fever with renal syndrome vaccine (Hantavax): consideration of active immunization in South Korea. Yonsei Med J 2001; 42(3):278-284.

8. Krüger DH, Schönrich G, Klempa B. Human pathogenic hantaviruses and prevention of infection. Hum Vaccin $2011 ; 7(6)$ : 685-693.

9. Avšič-Županc T, Saksida A, Korva M. Hantavirus infections. Clin Microbiol Infect 2019;21S:e6-e16.

10. Maes P, Clement J, Gavrilovskaya I, Van Ranst M. Hantaviruses: immunology, treatment, and prevention. Viral Immunol 2004; 17(4):481-497.

11. Yi Y, Park $\mathrm{H}$, Jung J. Effectiveness of inactivated hantavirus vaccine on the disease severity of hemorrhagic fever with renal syndrome. Kidney Res Clin Pract 2018;37(4):366-372.

12. Oberg AL, Kennedy RB, Li P, Ovsyannikova IG, Poland GA. Systems biology approaches to new vaccine development. Curr Opin Immunol 2011;23(3):436-443.

13. Schmaljohn CS. Vaccines for hantaviruses: progress and issues. Expert Rev Vaccines 2012;11(5):511-513.

14. Poland GA, Whitaker JA, Poland CM, Ovsyannikova IG, Kennedy RB. Vaccinology in the third millennium: scientific and social challenges. Curr Opin Virol 2016;17:116-125.

15. Oh SJ, Choi YK, Shin OS. Systems biology-based platforms to accelerate research of emerging infectious diseases. Yonsei Med J 2018;59(2):176-186.

16. Poland GA, Kennedy RB, McKinney BA, Ovsyannikova IG, Lambert ND, Jacobson RM, et al. Vaccinomics, adversomics, and the immune response network theory: individualized vaccinology in the 21st century. Semin Immunol 2013;25(2):89-103.

17. Poland GA, Ovsyannikova IG, Jacobson RM, Smith DI. Heterogeneity in vaccine immune response: the role of immunogenetics and the emerging field of vaccinomics. Clin Pharmacol
Ther 2007;82(6):653-664.

18. Pulendran B, Li S, Nakaya HI. Systems vaccinology. Immunity 2010;33(4):516-529.

19. De Gregorio E, Rappuoli R. Vaccines for the future: learning from human immunology. Microb Biotechnol 2012;5(2):149155.

20. Mooney M, McWeeney S, Sékaly RP. Systems immunogenetics of vaccines. Semin Immunol 2013;25(2):124-129.

21. Nakaya HI, Pulendran B. Vaccinology in the era of high-throughput biology. Philos Trans R Soc Lond B Biol Sci 2015;370(1671): 20140146.

22. Querec TD, Akondy RS, Lee EK, Cao W, Nakaya HI, Teuwen D, et al. Systems biology approach predicts immunogenicity of the yellow fever vaccine in humans. Nat Immunol 2009;10(1):116125.

23. Gaucher D, Therrien R, Kettaf N, Angermann BR, Boucher G, Filali-Mouhim A, et al. Yellow fever vaccine induces integrated multilineage and polyfunctional immune responses. J Exp Med 2008;205(13):3119-3131.

24. Ackerman ME, Barouch DH, Alter G. Systems serology for evaluation of HIV vaccine trials. Immunol Rev 2017;275(1):262-270.

25. Mooney M, McWeeney S, Canderan G, Sékaly RP. A systems framework for vaccine design. Curr Opin Immunol 2013;25(5): 551-555.

26. Circelli L, Petrizzo A, Tagliamonte M, Tornesello ML, Buonaguro FM, Buonaguro L. Systems biology approach for cancer vaccine development and evaluation. Vaccines (Basel) 2015;3(3):544555.

27. Petrizzo A, Tagliamonte M, Tornesello M, Buonaguro FM, Buonaguro L. Systems vaccinology for cancer vaccine development. Expert Rev Vaccines 2014;13(6):711-719.

28. Hagan T, Nakaya HI, Subramaniam S, Pulendran B. Systems vaccinology: enabling rational vaccine design with systems biological approaches. Vaccine 2015;33(40):5294-5301.

29. Poland GA, Ovsyannikova IG, Jacobson RM. Personalized vaccines: the emerging field of vaccinomics. Expert Opin Biol Ther 2008;8(11):1659-1667. 